\title{
Effect of the temperature, strain rate and microstructure on flow and fracture characteristics of $\mathrm{Ti}-45 \mathrm{Al}-2 \mathrm{Nb}-2 \mathrm{Mn}+0.8 \mathrm{vol} . \%$ $\mathrm{TiB}_{2} \mathrm{XD}$ alloy
}

B. Erice ${ }^{a}$, M.J. Pérez-Martín, D.A. Cendón, and F. Gálvez

\begin{abstract}
A series of quasi-static and dynamic tensile tests at varying temperatures were carried out to determine the mechanical behaviour of Ti-45Al-2Nb-2Mn+0.8vol. $\% \mathrm{TiB}_{2} \mathrm{XD}$ as-HIPed alloy. The temperature for the tests ranged from room temperature to $850^{\circ} \mathrm{C}$. The effect of the temperature on the ultimate tensile strength, as expected, was almost negligible within the selected temperature range. Nevertheless, the plastic flow suffered some softening because of the temperature. This alloy presents a relatively low ductility; thus, a low tensile strain to failure. The dynamic tests were performed in a Split Hopkinson Tension Bar, showing an increase of the ultimate tensile strength due to the strain rate hardening effect. Johnson-Cook constitutive relation was used to model the plastic flow. A post-testing microstructural of the specimens revealed an inhomogeneous structure, consisting of lamellar $\alpha_{2}+\gamma$ structure and $\gamma$ phase equiaxed grains in the centre, and a fully lamellar structure on the rest. The assessment of the duplex-fully lamellar area ratio showed a clear relationship between the microstructure and the fracture behaviour.
\end{abstract}

\section{Introduction}

The highly demanding aeronautical industry is constantly seeking lighter and more economically affordable materials that can be used as a replacement for the current ones. Finding a valid alternative to replace turbo-machinery component materials such as turbine blades fulfilling these characteristics presents a real challenge for the industry. That is the reason for the recent interest in $\gamma$-TiAl based alloys, with them becoming a tangible alternative to the nickel and cobalt based super-alloys commonly used for mechanical components subjected to high temperatures. The main advantage is the reduction of weight, since the density is round $3900 \mathrm{~kg} / \mathrm{m}^{3}$ for the former and $8250 \mathrm{~kg} / \mathrm{m}^{3}$ for the latter. Some leading companies from the aero-engine manufacturing sector have considered the future use of these type of alloys to replace low pressure 
turbine blades [1], at present made of precipitated wrought Inconel 718 nickel-based super-alloy. The $\gamma$-TiAl based alloys, such as the Ti-45Al-2Nb-2Mn+0.8vol.\% $\mathrm{TiB}_{2}$ XD (45XD), have well known physical properties such as low density, good corrosion resistance and a high melting temperature. Nevertheless, few studies have been carried out regarding tensile mechanical properties [2-4]. Due to its fragile nature, the mechanical properties of the 45XD alloy and other $\gamma$-TiAl based alloys usually assessed are based on fracture toughness testing. In this investigation, tensile properties of the 45XD alloy were analysed. Since the 45XD alloy is intended for use as low pressure turbine (LPT) blade, the material testing temperature ranged from room temperature to $850^{\circ} \mathrm{C}$, with this widely covering the real working temperature of such a component. An additional testing condition usually required for materials used as turbine components, is high strain rate testing. In the case of a blade-off event study inside a jet engine turbine, accurate knowledge of the mechanical behaviour of the material at high strain rates is required. In order to carry out numerical simulations of events that may occur inside jet engine turbines, such as tangling or containment in which XD45 alloy could be present, a suitable material model is necessary. The nature of these events implies that strain rate and temperature effects are important enough to be taken into account. Johnson-Cook (JC) constitutive relation [5] was used to model the plastic flow of XD45 alloy. Many have used this relation before modelling plastic flow and carrying out numerical simulations of high strain rate and impact phenomena with good results. When modelling the fracture behaviour of the XD45 alloy, some issues were encountered. Some authors $[1,6,7]$ have pointed out the close relation between the mechanical properties of $\gamma$-TiAl based alloys and their microstructure. The fracture behaviour of these kinds of alloys is especially sensitive to the type of microstructure [8]. The microstructure of the as-HIPed XD45 alloy was encountered as being far from homogenous, something that has also been found by other researchers $[1,9]$. In order to relate the microstructure with the fracture behaviour, a post-testing microstructure analysis was carried out. This revealed that strain to failure, as already stated, was microstructure dependent.

\section{Material tests}

Material testing for XD45 alloy was carried out at two different strain rates. The purpose of testing in these two regimes was to observe if the mechanical behaviour of the material was affected by the strain rate. As far as the authors know, in the literature there are few tensile tests at high strain rates of $\gamma$-TiAl based alloys. It should be noted that due to the low strain to failure values of 45XD alloys, material fails long before necking, being initial $\left(A_{0}\right)$ and instantaneous $(A)$ cross-section areas practically the same. Hence, there would be little benefit in distinguishing between engineering stress $s=F / A_{0}$ and true stress $\sigma=F / A$. Since 45XD alloy will be used as a mechanical component at high temperatures, mechanical properties should be analysed at the working temperature of the component. Therefore, tensile tests at various temperatures were carried out for the two strain rate regimes.

\subsection{Quasi-static tensile tests}

Quasi-static tensile tests of smooth axisymmetric specimens at room temperature, $500^{\circ} \mathrm{C}$ and $650^{\circ} \mathrm{C}$ were carried out. The tests were conducted under a strain rate of $5 \times 10^{-5} \mathrm{~s}^{-1}$ in an INSTRON servo hydraulic universal testing machine. A temperature chamber was used in order to achieve the desired temperature. It was equipped with two heat resistant quartz windows to allow recording of each test evolution with digital 
Table 1. UTS, fracture strain $\left(\varepsilon_{f}\right)$ and post-testing duplex structure area measurements.

\begin{tabular}{|c|c|c|c|c|c|c|}
\hline $\begin{array}{l}\text { Specimen } \\
\text { ID }\end{array}$ & $\begin{array}{c}\text { Temperature } \\
\left({ }^{\circ} \mathrm{C}\right)\end{array}$ & $\begin{array}{c}\varepsilon_{f} \\
(\%)\end{array}$ & $\begin{array}{c}\text { UTS } \\
(\mathrm{MPa})\end{array}$ & $\begin{array}{c}\mathrm{DP} \\
\text { area }\left(\mathrm{mm}^{2}\right)\end{array}$ & $\begin{array}{l}\text { Cross-section } \\
\text { area }\left(\mathrm{mm}^{2}\right)\end{array}$ & $\begin{array}{c}\text { DP-FL } \\
\text { area ratio (\%) }\end{array}$ \\
\hline \multicolumn{7}{|c|}{ Quasi-static tests $\left(\dot{\varepsilon}=5 \times 10^{-5} \mathrm{~s}^{-1}\right)$} \\
\hline $\mathrm{T} 21$ & $\mathrm{RT}(24)$ & 0.46 & 573 & 0.365 & 28.378 & 1.3 \\
\hline T15 & RT (24) & 0.54 & 586 & 0.095 & 28.436 & 0.3 \\
\hline T02 & 500 & 0.70 & 531 & 1.094 & 28.739 & 3.9 \\
\hline T03 & 500 & 0.78 & 545 & 2.270 & 28.748 & 8.0 \\
\hline Т05 & 650 & 1.24 & 532 & 0.220 & 28.683 & 0.8 \\
\hline T18 & 650 & 1.35 & 544 & 0.860 & 28.371 & 3.0 \\
\hline \multicolumn{7}{|c|}{ Dynamic tests $\left(\dot{\varepsilon}=3 \times 10^{2} \mathrm{~s}^{-1}\right)$} \\
\hline T01 & RT (24) & 0.58 & 645 & 0.398 & 28.719 & 1.40 \\
\hline T19 & $\mathrm{RT}(24)$ & 0.53 & 675 & 1.484 & 28.079 & 5.20 \\
\hline T16 & 552 & 1.57 & 719 & 5.571 & 28.403 & 19.70 \\
\hline $\mathrm{T} 17$ & 555 & 2.48 & 717 & 3.305 & 28.129 & 11.70 \\
\hline T04 & 557 & 0.75 & 669 & 1.447 & 28.777 & 5.10 \\
\hline T07 & 647 & 0.76 & 650 & 0.312 & 28.430 & 1.10 \\
\hline T10 & 649 & 1.10 & 583 & 2.997 & 28.649 & 10.60 \\
\hline T13 & 737 & 1.17 & 666 & 1.334 & 28.111 & 4.70 \\
\hline T09 & 739 & 0.76 & 717 & 0.875 & 28.202 & 3.10 \\
\hline $\mathrm{T} 20$ & 737 & 0.85 & 582 & 2.518 & 28.097 & 8.90 \\
\hline T06 & 857 & 0.74 & 640 & 2.979 & 28.449 & 10.50 \\
\hline T08 & 850 & 1.30 & 670 & 0.384 & 29.217 & 1.40 \\
\hline $\mathrm{T} 14$ & 830 & 0.75 & 593 & 1.661 & 28.284 & 5.90 \\
\hline
\end{tabular}

cameras. The temperature control of the chamber was regulated with a thermocouple in contact with the specimen. The strain for the tensile tests at room temperature was measured with a conventional extensometer, with the gauge length being $12.5 \mathrm{~mm}$ with $\pm 2.5 \mathrm{~mm}$ range. On the other hand, the strain measurement of the tests carried out at $500^{\circ} \mathrm{C}$ and $650^{\circ} \mathrm{C}$ were performed with a digital image correlation (DIC) system. It should be noted that some issues had been addressed in the past with measurements based on a two-dimensional DIC system at high temperatures [10]. To address such problems, a three-dimensional DIC system was used involving two digital cameras, instead of one used with the two-dimensional one. In order to obtain the strains from the images captured by the two cameras, DIC software provided by Correlated Solutions was used. The strains were calculated as $\varepsilon=\Delta l / l_{0}$, where $\Delta l$ is the elongation and $l_{0}$ is the initial length of the specimen (gauge length). Hence, the plastic strains from the experimental data were calculated as $\varepsilon_{p}=\varepsilon-\sigma / E$. Two specimens were tested at each temperature. Specimen IDs and testing temperatures are summarised in Table 1. The stress-strain curves obtained from the tensile tests are shown in Fig. 1a. A loss of stiffness with the temperature was noticed, the elastic modulus decreased with the temperature (see Fig. 1a). The relation between the elastic modulus and the temperature was found to be linear, as $E(T)=E_{a}+E_{b} T$, where $E$ is the elastic modulus, $T$ is the temperature and $E_{a}, E_{b}$ are linear fitting constants. The linear fit with $E_{a}=165.96 \mathrm{GPa}$ and $E_{b}=-0.04 \mathrm{GPa} /{ }^{\circ} \mathrm{C}$ is shown in Fig. 1b. Thermal softening was observed in the plastic flow (see Fig. 1b). Nevertheless, the ultimate tensile strength (UTS) values remained the same for the specimens tested at room temperature, $500^{\circ} \mathrm{C}$ and $650^{\circ} \mathrm{C}$. In this particular case, the lack of ductility of the XD45 alloy prevented the necking process. Thus, the maximum stress coincided with the ultimate value of it. When analysing the service conditions, due to the 

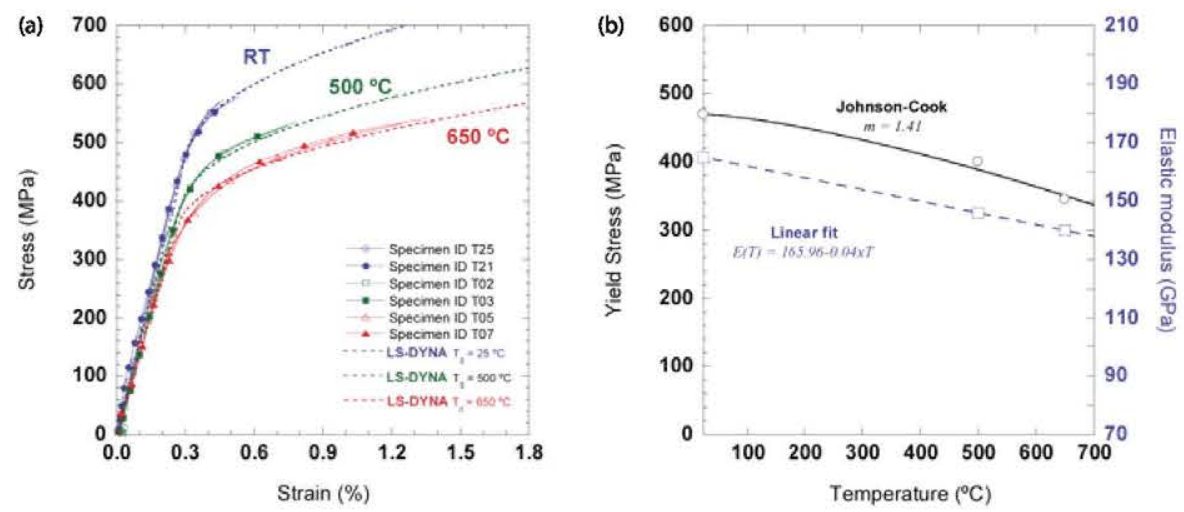

Fig. 1. (a) Stress-strain curves for the specimens tested at $\dot{\varepsilon}=5 \times 10^{-5} \mathrm{~s}^{-1}$ compared with the numerical simulations. (b) Variation of yield stress and elastic modulus with the temperature.

characteristics of the XD45 alloy, it is obvious that the values to be assessed should be UTS and strain to failure. Almost no differences were encountered, in terms of UTS values, between the specimens tested at room temperature, $500^{\circ} \mathrm{C}$ and $650^{\circ} \mathrm{C}$ (see Fig. 2b). On the other hand, strains to failure values were larger for higher temperatures. Strain to failure for the tests performed at $650^{\circ} \mathrm{C}$ increased by almost three times its value compared with those carried out at room temperature.

\subsection{Dynamic tensile tests}

A Split Hopkinson Tension Bar (SHTB) was used to carry out tensile tests of axisymmetric smooth specimens. The tension configuration of the SHTB was used to perform tensile tests. The temperature chamber installed in the SHTB allowed testing of the specimens at various temperatures. The temperature chamber was controlled by a thermocouple attached to the specimen. In this configuration of the SHTB, in order to maintain the properties of the bars as constant as possible with the temperature, two René 41 nickel based super-alloy bars were used as input and output bars. The specimens were tested at room temperature, $550^{\circ} \mathrm{C}, 650^{\circ} \mathrm{C}, 740^{\circ} \mathrm{C}$ and $850^{\circ} \mathrm{C}$. The input bar was $8050 \mathrm{~mm}$ in length and the output $3850 \mathrm{~mm}$. The diameter of both bars was $19.05 \mathrm{~mm}$. The striker bar was a $2000 \mathrm{~mm}$ long tubular bar. It was launched with compressed air in the opposite direction of the wave propagation. The striker bar impact caused a tensile elastic wave, the incident wave. With this SHTB configuration the incident wave pulse length was around $800 \mu \mathrm{s}$. The wave travelled along the input bar until it reached the specimen. Material and geometry mismatch caused a reflected and transmitted wave. These three waves could be decomposed in strains which affect input and output bars. Incident $\left(\varepsilon_{i}\right)$ and reflected $\left(\varepsilon_{r}\right)$ strains affect the input bar and transmitted strain affects $\left(\varepsilon_{t}\right)$ the output bar. The strain history was recorded with strain gauges attached to the input and output bars. The use of strains or stresses is equivalent, given that the bars are constantly in elastic regime. According to the elastic unidimensional wave propagation theory and its application to the SHTB [11], the stress, strain and the strain rate of the specimen can be calculated as:

$$
\sigma=\frac{F_{s}}{A_{s}}=\frac{E_{b} A_{b}}{A_{s}} \varepsilon_{t} ; \varepsilon=-\frac{2 c_{0}}{l_{s}} \int_{0}^{t} \varepsilon_{r} \mathrm{~d} t ; \dot{\varepsilon}=-\frac{2 c_{0}}{l_{s}} \varepsilon_{r}
$$


(a)

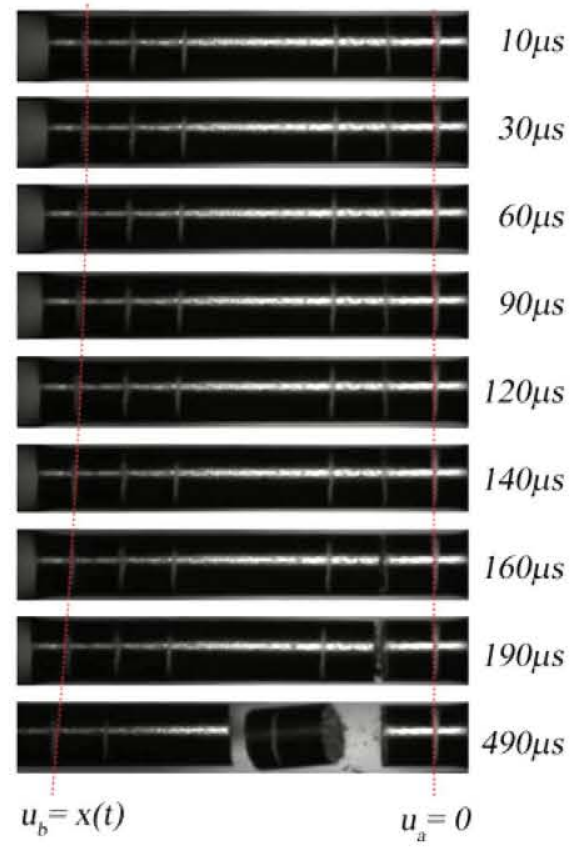

(b)

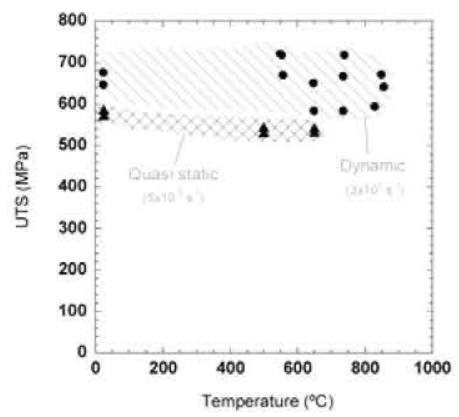

(c)

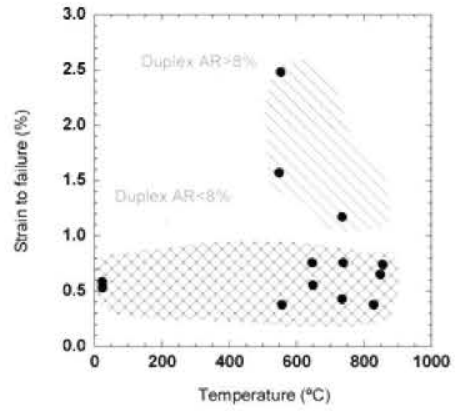

Fig. 2. (a) High speed video of a SHTB test at $555^{\circ} \mathrm{C}$. (b) UTS values for quasi-static and dynamic tests. (c) Strain to failure values divided in regions attending to the Duplex area ratio.

where $F_{s}$ is the force applied by the input bar over the specimen, $E_{b}$ is the elastic modulus of the bars, $A_{b}$ is the cross section area of the bars, $A_{s}$ is the initial cross section area of the specimen, $c_{0}=\sqrt{E_{b} / \rho_{b}}$ is the elastic wave velocity in the bars, $\rho_{b}$ is the density of the bars and $l_{s}$ is the length of the specimen.

As an additional measurement system to the strain gauges, a Phantom v12 high speed camera was used. The camera was configured to achieve 100000 frames per second. The high speed camera requires a massive amount of light due to the low exposure time. Two lamps were installed focussing the specimen in order to capture the images as being as sharp as possible. The temperature chamber remained closed until the experiment started. A pneumatic system was installed in the temperature chamber. This system consisted of a pneumatic actuator which moves the temperature chamber along rails until opening and allowed filming of the tests. The furnace was in its open position for only $300 \mathrm{~ms}$, so the temperature of the specimen was considered the same as the furnace temperature. The recordings of the high speed camera allowed measuring the time until fracture occurred. The camera was set up in order to start recording when the incident wave reached the second strain gauge. The time $(t)$ that an elastic stress wave takes to travel a certain distance $(L)$ is $t=L / c_{0}$. In this case, the time that takes to travel from the strain gauge to the specimens is around $400 \mu \mathrm{s}$. The test time was then obtained by subtracting this last time to the one that was recorded with the camera. The shortest test time period observed in the recordings was $160 \mu \mathrm{s}$. The specimen must be in equilibrium to achieve the stress uniformity. This occurs when the stress wave travels through the $n$ times from one end to another of the specimen. The total time $\left(t_{b}\right)$ required for stress equilibrium is then $t_{b}=n L_{0} / c$, where $L_{0}$ is the initial length of the specimen and $c$ is the elastic stress wave velocity in the specimen. In this particular case according to [12] $n$ is between 9 and 13 assuming a perfectly rectangular incident pulse and $n$ is equal to 3 assuming an incident pulse 

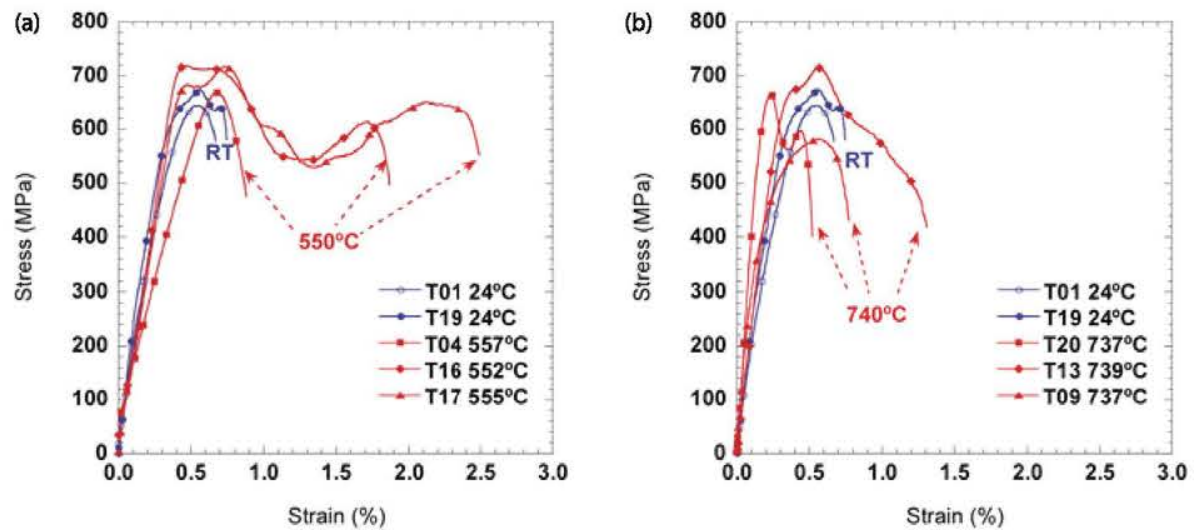

Fig. 3. Stress-strain curves of the dynamic $\left(\dot{\varepsilon}=3 \times 10^{2} \mathrm{~s}^{-1}\right)$ tensile tests at $550^{\circ} \mathrm{C}$ (a), $740^{\circ} \mathrm{C}(\mathrm{b})$ and room temperature.

with a finite rise time. Assuming the worst case, $n=13$ the time for stress equilibrium is $t_{b}=71 \mu \mathrm{s}$. The shortest test time was more than twice the time to reach the stress equilibrium. All the specimens tested were then in stress equilibrium.

In the previous section low values of strain to failure were addressed, even for tests carried out at $650^{\circ} \mathrm{C}$. The same behaviour was encountered for the dynamic tests. Low strain to failure could be translated into low time to failure. This causes some issues when measuring strains with the high speed camera. The specimen fails with too low deformation, which made strain measuring very troublesome. The low deformation until failure of the specimens can be observed in Fig. 2. Only strain to failure measurements were taken. The specimens were marked with heat resistant painting in order to track the distances between transversal lines (see Fig. 2a).

The stress-strain curves of the tensile tests performed in the SHTB at $550^{\circ} \mathrm{C}$ and $740^{\circ} \mathrm{C}$ are shown in Fig. 3. All of them are compared with the tests carried out at room temperature. Observing the stress-strain curves (see Fig. 3) for the dynamic tests, it was noted that the UTS hardly varied. This was also the case of the quasistatic tests (see the previous section). However, under closer observation, some of the specimens presented more accumulated plastic strain before fracture for the same testing temperature. Such a case is that of the specimens with IDs T17 and T04 tested at $550^{\circ} \mathrm{C}$ (see Fig. 3a). Therefore, strain to failure values are quite closely affected by this fact. In addition to this, the microstructure played a highly significant role in these effects as will be explained in subsequent sections.

\section{Plastic flow modelling}

\subsection{Johnson-Cook constitutive relation}

Johnson-Cook constitutive relation [5] is a widely used expression for impact and high strain rate phenomena. Most non-linear finite element method codes have JC model already implemented. This expression, which is relatively simple and quite versatile, models the flow behaviour of the equivalent flow stress, $\bar{\sigma}=\sqrt{3 J_{2}}=\sqrt{3 / 2 \sigma^{\prime}: \sigma^{\prime}}$ where $J_{2}$ is the second invariant of the deviatoric stress tensor $\sigma^{\prime}=\sigma-1 / 3 \operatorname{tr}(\sigma) \boldsymbol{I}$, $\sigma$ is the Cauchy stress tensor and $\boldsymbol{I}$ is the second-order identity tensor. It is separated into three independent terms, which multiply each other (see Eq. (3)). The first term represents the strain hardening of the material, the second the strain rate 
Table 2. Johnson-Cook constitutive relation material constants for Ti-45Al-2Nb$2 \mathrm{Mn}+0.8 \mathrm{vol} . \% \mathrm{TiB}_{2} \mathrm{XD}$ alloy.

\begin{tabular}{|c|c|c|c|c|c|c|}
\hline \multicolumn{3}{|c|}{ Elastic constants } & \multicolumn{4}{|c|}{ Physical properties } \\
\hline $\mathrm{E}(\mathrm{GPa})$ & \multicolumn{2}{|l|}{$\nu$} & \multicolumn{2}{|c|}{$\rho\left(\mathrm{kg} / \mathrm{m}^{3}\right)$} & $C_{p}\left(\mathrm{~J} / \mathrm{kg}^{\circ} \mathrm{C}\right)$ & $\chi$ \\
\hline 165 & \multicolumn{2}{|l|}{0.3} & \multicolumn{2}{|c|}{$3700-3900$} & 500 & 0.9 \\
\hline \multicolumn{3}{|c|}{ Strain hardening } & \multicolumn{2}{|c|}{ Strain rate hardening } & \multicolumn{2}{|c|}{ Thermal softening } \\
\hline$A(\mathrm{MPa})$ & $B(\mathrm{MPa})$ & $n$ & $C$ & $\dot{\varepsilon}_{0}\left(\mathrm{~s}^{-1}\right)$ & $m$ & $T_{m}\left({ }^{\circ} \mathrm{C}\right)$ \\
\hline 497 & 2045 & 0.45 & 0.021 & $5 \times 10^{-5}$ & 1.41 & 1680 \\
\hline
\end{tabular}

hardening and the third the thermal softening. The effect of each one of the phenomena is considered independent. Other authors [13] have addressed the combined effects of temperature and strain rate. Since the model is purely empirical, does not take into account the strain-rate of temperature history effects. Only five material constants are necessary to model the plastic flow of the material. The JC constitutive relation is:

$$
Y_{J C}=\left[A+B \bar{\varepsilon}_{p}^{n}\right]\left[1+C \ln \dot{\bar{\varepsilon}}_{p}^{*}\right]\left[1-T^{* m}\right]
$$

where $\bar{\varepsilon}_{p}$ is the equivalent plastic strain, $\dot{\bar{\varepsilon}}_{p}^{*}$ is the dimensionless plastic strain rate where $\dot{\varepsilon}_{p}$ is the equivalent plastic strain rate and $\dot{\varepsilon}_{0}$ is a user defined reference strain rate; and $T^{*}=\left(T-T_{r}\right) /\left(T_{m}-T_{r}\right)$ is the homologous temperature where $T$ is the temperature, $T_{r}$ is the room temperature and $T_{m}$ is the melting temperature. $A, b, n$, $C$ and $m$ are the five material constants (see Table 2). Assuming adiabatic conditions, the temperature increment due to plastic work can be calculated as:

$$
\Delta T=\frac{\chi}{\rho C_{p}} \boldsymbol{\sigma}: \Delta \varepsilon_{p}
$$

where $\chi$ is the Taylor-Quinney coefficient, $\rho$ is the density $C_{p}$ is the specific heat and $\dot{\varepsilon}_{p}$ is the plastic strain rate tensor. Physical properties and $\mathrm{JC}$ constitutive relation material constants for XD45 alloy are summarised in Table 2.

\subsection{Constant identification}

Five constants are necessary for the calibration of the JC constitutive relation [5] (Eq. (2)). The first three constants represent the strain hardening of the material. The first one, $A$ can be related to the yield stress and the other two, $B$ and $n$, are strain hardening multiplier and exponent respectively. In order to calibrate the first three constants, quasi-static tensile tests at room temperature are usually required. The low ductility of the XD45 alloy at room temperature implies that setting the yield stress at $0.2 \%$ offset loses all the non-linear behaviour from the stress-strain curve. Therefore, in order to conserve the non-linear behaviour intact, the yield stress offset used for the calibration of JC constitutive relation was set at $0.02 \%$. $A, B$ and $n$ were adjusted conveniently using a reference strain rate $\dot{\varepsilon}=5 \times 10^{-5} \mathrm{~s}^{-1}$, the strain rate at which the quasi-static tensile tests were performed. The JC model plastic flow for equivalent stress at room temperature compared with the experimental register is shown in Fig. 4. The fourth constant, $C$, represents the strain hardening of the material and is usually determined with yield stress values at different strain rates. In this particular case, due to that stated in the previous paragraph and the obvious 

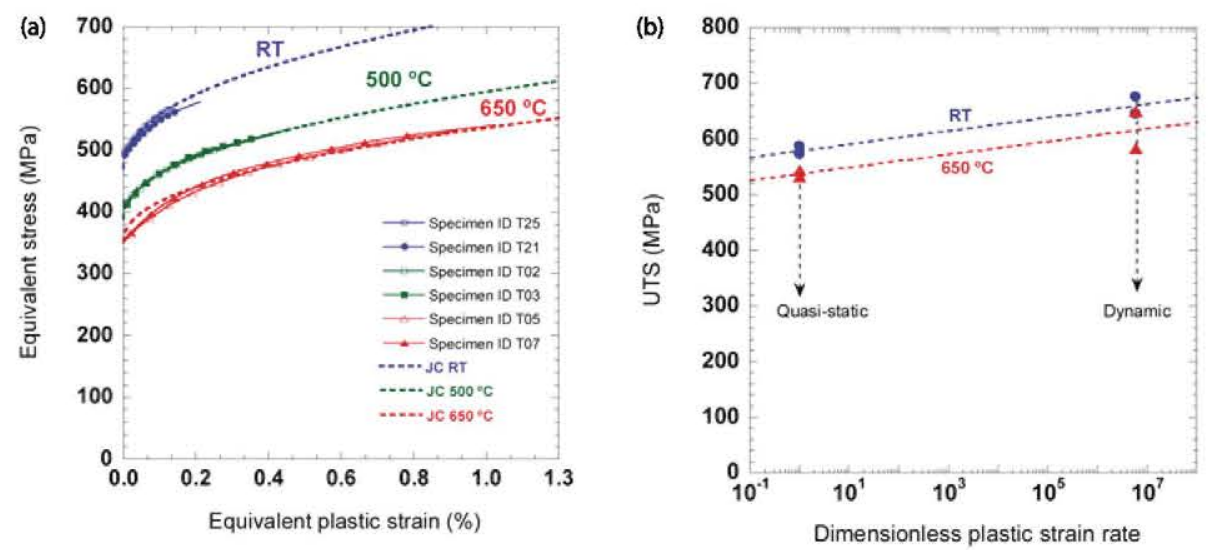

Fig. 4. (a) Johnson-Cook flow stress fitted with experimental data compared with the equivalent stress-equivalent plastic strain curves at quasi-static conditions. (b) UTS vs. $\log$ arithmic dimensionless strain rate for tensile tests at room temperature and $650^{\circ} \mathrm{C}$.

difficulty of obtaining yield stress from the SHTB data (see Fig. 3), the authors considered that comparing UTS values at low and high strain rates should have had enough consistency to calibrate the constant. The UTS values were compared for low and high strain rates at the coincident temperatures between the two test regimes, i.e. room temperature and $650^{\circ} \mathrm{C}$. The constant value was encountered as being quite consistent, almost equal for both temperatures (see Fig. $4 \mathrm{~b}$ ). The fifth and last constant, $m$, is the thermal softening exponent. To calibrate this, only the yield stress values from the quasi-static tests corresponding to $0.02 \%$ offset were used. The variation of the yield stress with the temperature and the JC fit is shown in Fig. 1b. In order to assure the consistency of the JC model of the equivalent stress plastic flow was plotted with the experimental equivalent stress vs. equivalent plastic strain curves (see Fig. 4a). The results were more than satisfactory for all the temperatures.

\subsection{Numerical simulations}

The constant identification, as explained in the previous section, was made directly from experimental data. In order to have a more accurate computational constitutive model when simulating the plastic flow of 45XD alloy, the values of $A, B, n, C$ and $m$ obtained from the experimental calibration were used as a starting point in an inverse modelling process. This process was performed by simulating a finiteelement model of the specimens tested in quasi-static and dynamic conditions at various temperatures. LS-DYNA [14] non-linear finite element code was used to carry out the numerical simulations. JC model implemented in LS-DYNA does not offer the possibility to set an initial temperature for the elements unless a thermal analysis is performed. The coupled structural-thermal analysis increases substantially the computational time in the simulations. In order to save that time a user defined material subroutine was implemented. The user defined material subroutine was implemented using a classical von Mises yield criterion using the JC constitutive relation (see Eq. (2)). The yield function then reads:

$$
\phi=\bar{\sigma}(\sigma)-Y_{J C}\left(\bar{\varepsilon}_{p}, \dot{\varepsilon}_{p}, T\right)
$$

where $\dot{\varepsilon}_{p}=\sqrt{2 / 3 \dot{\varepsilon}_{p}: \dot{\varepsilon}_{p}}$ is the equivalent plastic strain rate. The flow rule was chosen associative, which implied that von Mises yield function was adopted as flow potential 
being the equivalent plastic strain rate tensor:

$$
\dot{\varepsilon}_{p}=\dot{\lambda} \frac{\partial \phi}{\partial \boldsymbol{\sigma}}=\dot{\lambda} \frac{3}{2} \frac{\boldsymbol{\sigma}^{\prime}}{\bar{\sigma}}
$$

where $\lambda$ is the plastic multiplier. Introducing Eq. (6) in the definition of the equivalent plastic strain rate gives $\dot{\lambda}=\dot{\bar{\varepsilon}}_{p}$. Substituting the plastic multiplier in Eq. (6) lead to Prandtl-Reuss flow rule. The stress tensor was updated in each time step by using the radial scaling method introduced by [15]. This has also been successfully tested and implemented in [16]. The temperature was stored as a history variable in the user defined material subroutine. The subroutine started setting $T=T_{0}$ being $T_{0}$ the initial temperature and was computed in each time step as $T_{n+1}=T_{n}+\Delta T$ (see Eq. (3)). The curve which shows the thermal softening effect (Fig. 1b) was constructed with the room temperature as reference. Hence, $24^{\circ} \mathrm{C}$ must always be the reference temperature. The quasi-static tensile tests of the smooth rounded specimens were simulated using an axisymmetric finite element model. The element size used within the gauge length was $0.1 \times 0.1 \mathrm{~mm}^{2}$. All the numerical simulations were ran with quasi-static loading conditions making sure that no dynamic effects were introduced in the material. The stress-strain curves were obtained monitoring the reaction forces in the constrained nodes and the displacement of two nodes with the same gap distance as the strain gauge used in the experiments. The first simulation was run with the constants calibrated with the experimental data (see previous section) and setting the temperature of the elements at room temperature $\left(T_{0}=24^{\circ} \mathrm{C}\right.$, $T_{r}=24^{\circ} \mathrm{C}$ ). The yield stress and the hardening parameters were adjusted by trial and error until a good correlation was obtained between the experimental and numerical stress-strain curves. The constants fitted with the numerical simulations are resumed in Table 2. The simulations corresponding to the quasi-static tensile tests at $500^{\circ} \mathrm{C}$ and $650^{\circ} \mathrm{C}$ where carried out with the constants from Table 2 just changing $T_{0}=500^{\circ} \mathrm{C}$ and $T_{0}=650^{\circ} \mathrm{C}$ respectively. The stress-strain curves obtained from the numerical simulations can be observed in Fig. 1a. For the numerical simulations of the dynamic tests the same mesh size as in the quasi-static finite element model was used. Simulating the specimen without the bars might cause undesired disturbances in the force computation. The elastic wave reflections in the specimen end might cause that effect [17]. In order to avoid such effects the input and output bars were introduced in the finite element model. The JC constants summarized in Table 2 were used to model the specimen. The bars were modelled as an elastic isotropic material with $\rho=8420 \mathrm{~kg} / \mathrm{m}^{3}, E=218 \mathrm{GPa}$ and $\nu=0.3$. The contact between the specimen and the bars was modelled merging the nodes from both specimen and bar ends. The loading was defined as a prescribed velocity against time taken from the experimental data from the dynamic test. The prescribed motion was applied in all the free end nodes of the input bar. The simulations were ran using five different values of $T_{0}, 24$ ${ }^{\circ} \mathrm{C}, 550^{\circ} \mathrm{C}, 650^{\circ} \mathrm{C}, 740^{\circ} \mathrm{C}$ and $850^{\circ} \mathrm{C}$. The numerical simulations gave a reasonable agreement with the experimental data for all the temperatures. Stress-strain curves obtained from the numerical simulations for $T_{0}=650^{\circ} \mathrm{C}$ and $T_{0}=740^{\circ} \mathrm{C}$ can be seen in Fig. 5a and Fig. 5b respectively.

\section{Post-testing microstructural and fractographic analysis}

Some researchers $[6]$ have pointed out the extreme importance of the microstructure on fracture behaviour $\gamma$-TiAl based alloys. The casting process of such alloys leaves considerable porosity. In this particular case the XD was used, with the process adding $\mathrm{Al}_{-}-\mathrm{TiB}_{2}$ to the melted base alloy produces a dispersion of $\mathrm{TiB}_{2}$ particles [18]. The use of such a manufacturing process reduces the grain size, increases the strength and 

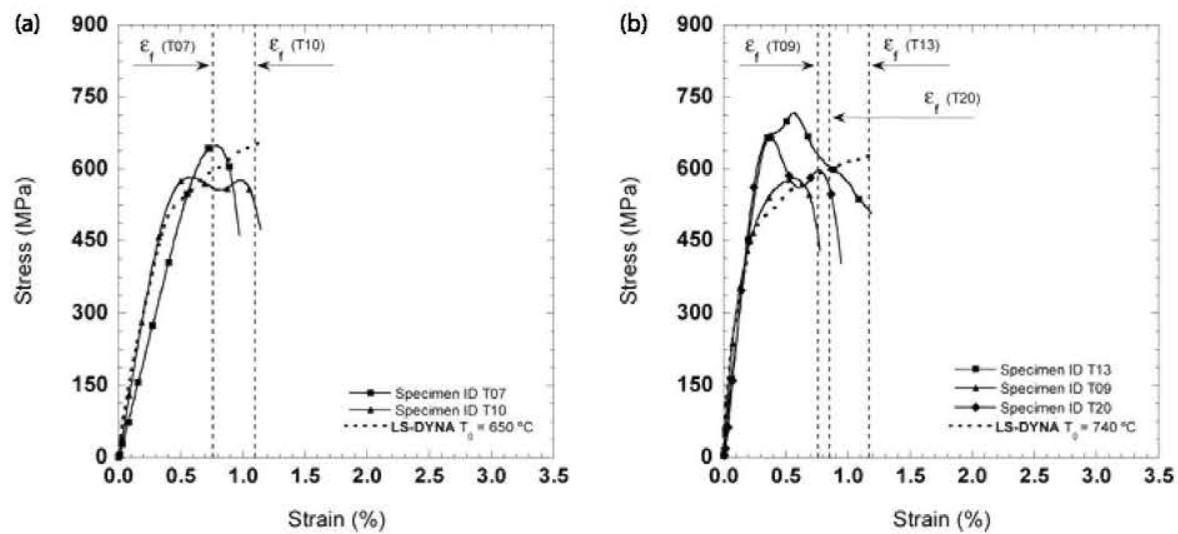

Fig. 5. Stress-Strain curves obtained from the numerical simulations at room $650^{\circ} \mathrm{C}$ (a) and $740^{\circ} \mathrm{C}$ (b) compared with the experimental register of the corresponding dynamic tests.

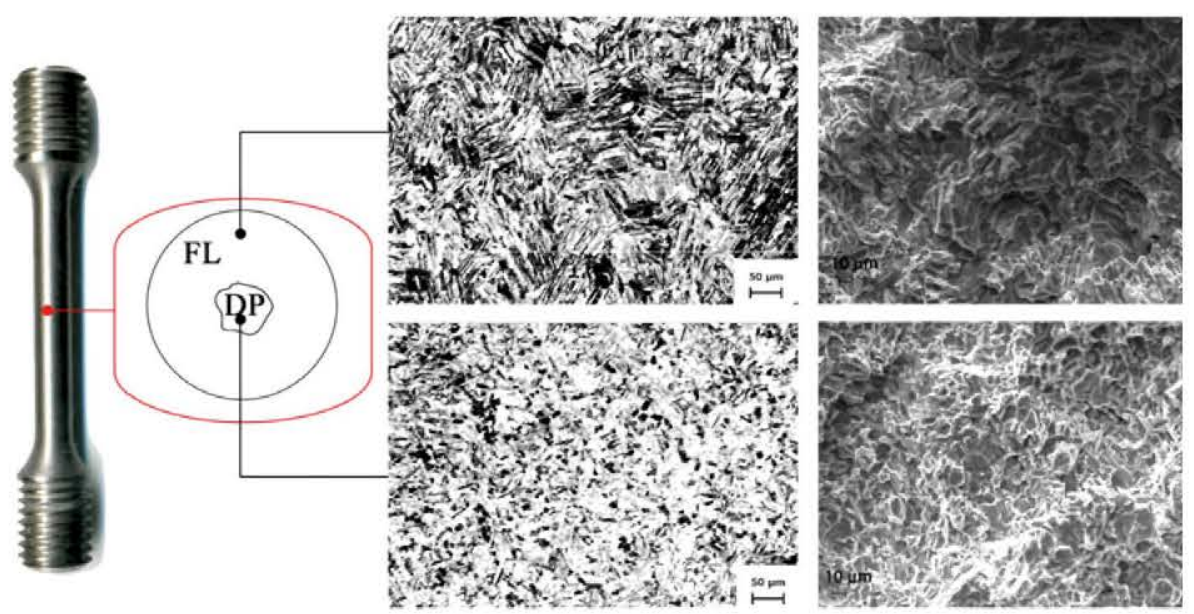

Fig. 6. Fully lamellar (top left) microstructure in the specimens exterior cross section area. (bottom left) Duplex (DP) microstructure in the interior cross section area. SEM images from the fracture surface of the specimen ID T17. Images taken from the center of the cross section area (bottom right) and from the edge (top right).

gives microstructural uniformity [19]. However, porosity is not overcome with the XD process. The hot isostatic pressing process is the usual to cope with this problem. More microstructural uniformity can be achieved with hot isostatic pressing (HIP) + heattreatment processes. In this particular case, as-HIP processed material was analysed. With it being known from previous studies $[4,6,8]$ that microstructure takes a strong role in the fracture behaviour of these kinds of alloys, post-testing microstructural analysis was performed. The most notable difference between strain to failure values was observed in the specimens tested in the SHTB. Thus, only the specimens tested at high strain rate were analysed. Metallographic specimens were obtained by cutting the original specimens along the cross section. The metallographic specimens were polished and etched using distilled water at $99 \%+$ HF $1 \%$ solution for 60 seconds. This procedure was carried out for all specimens tested at room temperature, $550^{\circ} \mathrm{C}$, $650^{\circ} \mathrm{C}, 740^{\circ} \mathrm{C}$ and $850^{\circ} \mathrm{C}$. The microstructure observed in all the specimens followed the pattern shown in Fig. 6. The central part of the cross sections analysed was composed of a duplex structure (DP), while the outer region was fully lamellar (FL). 
The former (DP structure) is composed of $\gamma$ equiaxed grains and lamellar colonies, while the latter (FL structure) is composed of alternate $\mathrm{Ti}_{3} \mathrm{Al}\left(\alpha_{2}\right)$ and $\mathrm{TiAl}(\gamma)$ plates [20]. The DP structure area was measured for all the specimens. In order to obtain a quantitative indicator, the DP-FL area ratio was defined (see Table 1). In accordance with such a DP-FL area ratio, strain to failure values of the specimens tested were analysed and classified. A change on the strain to failure was noticeable when the DP-FL area ratio exceeded $8 \%$ (see Fig. 2c). Of course, the authors are aware that the line traced at $8 \%$, in which the change occurs, is blurry. Nevertheless, the change is to a certain extent visible and the influence of DP structure on the specimens, even in small quantities, cannot be neglected. Summarising, the DP structure improves the tensile strain to failure of the XD45 alloy. No trace of improvement was found for UTS values, at least with the DP-FL area ratios of these specimens.

A fractographic analysis was carried out to investigate the fracture mechanisms of the different microstructures found in the post testing analysis. Scanning electron microscopy (SEM) images from the fracture surfaces of the centre and border of the specimens were taken, making sure that the microstructure was DP and FL respectively. In the Fig. 6 (top right), corresponding to a DP microstructure showed intergranular fracture of equiaxed grains. On the other hand in the Fig. 6 (bottom right), especially on left side of the image, quasi-cleavage of laminar grains was observed. The fractographic analysis then confirmed that DP microstructure seems to be beneficial for improving the tensile properties of 45XD alloy.

\section{Conclusions}

In this research the tensile properties of $\mathrm{Ti}-45 \mathrm{Al}-2 \mathrm{Nb}-2 \mathrm{Mn}+0.8 \mathrm{vol} . \% \mathrm{TiB}_{2} \mathrm{XD}$ as-HIP processed alloy at various strain rates and temperature have been studied. JohnsonCook constitutive relation constants for the studied material were obtained, modelling the plastic flow of the equivalent stress. The feasibility of simulating the plastic flow at various strain rates and temperatures has been demonstrated implementing an user material subroutine in LS-DYNA finite element code. A post-testing microstructural analysis was carried out in order to ensure that fracture behaviour was related to the microstructure of the specimens.

The subsequent conclusions were obtained from the present research:

- The XD45 alloy presented a very low ductility. Fracture occurred with very low deformation: no necking was addressed.

- No appreciable difference was encountered on the UTS values at different temperatures for the quasi-static tensile test. The same behaviour was observed for the dynamic tensile tests. Nevertheless, these values underwent an increase due to strain rate hardening effect.

- In the dynamic tensile tests of axisymmetric smooth specimens, different behaviours were observed for the specimens tested at the same temperatures. Some specimens accumulated more plastic strain than others before fracture. This behaviour was attributed to the differences in the microstructure.

- Post-testing microstructural analysis showed, as previously stated [4], that duplex microstructure was beneficial for the tensile properties of the XD45 alloy. This affirmation was confirmed analysing the fracture mechanisms of the DP and FL microstructures with SEM images of the fracture surfaces.

The authors would like to acknowledge the financial support through projects CONSOLIDER INGENIO 2010 and BIA2011-24445 of the Spanish Ministry of Science and Innovation. 


\section{References}

1. J.-H. Jeon, A.B. Godfrey, P.A. Blekinsop, W. Voice, Y.-D. Hahn, Mater. Sci. Eng. A $122(1999)$

2. D. Lin, Y. Wang, J. Liu, C.C. Law, Intermetallics 8, 549 (2000)

3. X. Zan, Y. Xia, Y. He, Mater. Sci. Eng. A 498, 296 (2008)

4. R.T. Zheng, Y.G. Zhang, C.Q. Chen, G.A. Cheng, Mater. Sci. Eng. A 362, 192 (2003)

5. G.R. Johnson, W.H. Cook, A Constitutive Model and Data for Metals Subjected to Large Strains, High Strain Rates and High Temperatures, in: 7th International Symposium on Ballistics (The Hague, 1983), p. 541

6. J.P. Campbell, K.T. Venkateswara Rao, R.O. Mater. Sci. Eng. A 239, 722 (1997)

7. J.P. Campbell, K.T. Venkateswara Rao, R.O. Ritchie, Metall. Mater. Trans. A 30, 563 (1999)

8. R. Gnanamoorthy, Y. Mutoh, Y. Mizuhara, Intermetallics 4, 525 (1996)

9. D.Y. Seo, L. Zhao, J. Beddoes, Mater. Sci. Eng. A 331, 130 (2002)

10. B. Erice, F. Gálvez, D.A. Cendón, V. Sánchez-Gálvez, Eng. Fract. Mech. 79, 1 (2012)

11. H. Kolsky, Stress Waves in Solids (Dover Publications, New York, 1963)

12. L.M. Yang, V.P.W. Shim, Int. J. Impact Eng. 31, 129 (2005)

13. T. Holmquist, G.N. Johnson, J. Phys. IV (France) (1991)

14. LS-DYNA KEYWORD USER'S MANUAL Version 971, Livermore Software Technology Corporation, Livermore, California (2007)

15. M.L. Wilkins, Computer Simulation of Dynamic Phenomena (Springer-Verlag, Berlin, Heidelberg, New York, 1999)

16. S. Chocron, B. Erice, C.E. Anderson, Int. J. Impact Eng. 38, 755 (2011)

17. T. Børvik, O.S. Hopperstad, T. Berstad, Eur. J. Mech. - A/Solids 22, 15 (2003)

18. D.E. Larsen, L. Chistodoulou, S.L. Kampe, P. Sadler, Mater. Sci. Eng. A 144, 45 (1991)

19. S.L. Kampe, P. Sadler, L. Christodoulou, D.E. Larsen, Metall. Mater. Trans. A 25, 2181 (1994)

20. Y.H. Wang, J.P. Lin, Y.H. He, Y.L. Wang, G.L. Chen, J. Alloys Comp. 468, 505 (2008) 